\title{
Study on Tobacco Agriculture Insurance Service System in Guizhou Province
}

\author{
Renze Wan Shaodong Ma Shiyun Guan \\ School of Finance, Guizhou University of Finance and Economics, Guiyang 550025, \\ China
}

\begin{abstract}
Based on the research data, this paper uses fuzzy comprehensive evaluation method to evaluate the quality of tobacco agricultural insurance service in Guizhou province. The results show that tobacco farmers are basically satisfied with the tobacco agricultural insurance service system. In view of the problems existing in the tobacco agricultural insurance service system, Suggestions are made from different perspectives such as government and insurance companies.
\end{abstract}

\section{Keywords}

Guizhou Province; Tobacco agriculture insurance; Fuzzy comprehensive evaluation

\section{贵州省烟草农业保险服务体系研究}

\author{
万仁泽 马绍东 管士云 \\ 贵州财经大学金融学院, 贵阳 550025, 中国
}

摘要:本文基于调研数据利用模糊综合评价法对贵州省烟草农业保险服务质量进行评价。结果 表明，烟农对烟草农业保险服务体系基本满意。针对烟草农业保险服务体系中存在的问题， 从政府、保险公司等不同行为主体的角度提出建议.

关键词：贵州省；烟草农业保险；模糊综合评价法

\section{Preface}

Guizhou is in low latitudes and high elevations. The climate type belongs to 
the central Asian monsoon humid climate, which is suitable for the growth and development of high-quality tobacco leaves. Tobacco industry is the pillar industry of Guizhou province. Therefore, this paper selects tobacco agricultural insurance as the representative of policy agriculture insurance in Guizhou province, and analyzes the existing problems of tobacco agricultural insurance service system. Then Put forward reasonable Suggestions on the basis of existing problems.

At present, both at home and abroad on the study of the theory of the agricultural insurance is relatively mature. But on the less developed regions such as Guizhou, agricultural insurance problem research is relatively lack. This article attempts to solve the problem.

\section{The present situation of tobacco agricultural insurance}

\subsection{Development of tobacco agricultural insurance in Guizhou province}

Since 1985, Guizhou province began to undertake tobacco cultivation insurance. After 1991, 47 counties (cities) of Anshun, Qiandongnan, Zunyi and Tongren carry out insurance business. During the period from 1991 to 1996 , the total insurance coverage was 532.24 million mu. The premium income was 3199.40 thousand yuan, and the payment of compensation was 3044.90 million yuan. The operating expenses were calculated at $25 \%$ of the total cost of RMB 799.850,000, and the party lost 645.35 million yuan in six years. As a state-owned insurance company that underwrites tobacco agricultural insurance, it is necessary to consider the interests of the company and social benefits. Because the tobacco insurance is not large-scale, insurance company can not effectively spread the risk of their own cases. This problem severely restricted the agricultural insurance risk fund accumulation. Since 1994 to 2007, flue-cured tobacco insurance business in Guizhou province ground to a halt.

To further perfect the flue-cured tobacco production risk guarantee system, effectively reduce the risk of flue-cured tobacco planting and fully arouse the enthusiasm of tobacco farmers planting flue-cured tobacco, the Guizhou province tobacco monopoly bureau which in conjunction with the China insurance regulatory commission regulatory authority in Guizhou and the Chinese people's property insurance co, LTD. promote the tobacco planting insurance pilot (2011-2013).

The insured liability includes rainstorm, flood, water logging, storm, hail, freeze, drought, disease and insect pests. The insurance amount is RMB 400 per mu, with an additional risk of 200 yuan per mu. The premium rate is $5 \%$; Additional 
insurance rate of $2 \%$. Insurance premium is 20 yuan $/ \mathrm{mu}$, additional insurance 4 yuan/mu, total premium is 24 yuan/mu. The county tobacco department, the county government, and the tobacco farmers are responsible for the corresponding portion of the premiums according to the ratio of 5:3:2. In 2011, the premiums of the county tobacco department, the pilot local government, and the tobacco farmers are 12 yuan, 7.2 yuan and 4.8 yuan per mu. At the same time, the pilot local government is exempted from the business tax of tobacco cultivation insurance for the insurance agencies that operate the policy-based agricultural insurance.

\subsection{Satisfaction survey of tobacco agricultural insurance service in Guizhou province}

Insurance service quality evaluation is the activity which purpose is very strong, the main body of insurance service quality evaluation can be either the insurance industry, also can be the manager of insurance enterprise and the recipients of insurance service. The satisfaction evaluation of insurance consumers is directly related to the success or failure of insurance companies. Therefore, for tobacco agricultural insurance, we select farmers as the evaluation subjects for the quality of insurance service.

This survey was conducted in the areas of Qiandongnan, Puan, Qiannan and Bijie.
This survey was conducted into the household survey. 110 questionnaires were issued and 110 questionnaires were collected. All of them were valid questionnaires.

Survey results showed that planting flue-cured tobacco farmer's age structure is: $39 \%$ of working families in $25 \sim 40$ years old, $53.64 \%$ of working families in $41 \sim 60$ years old, under the age of 25 and over 60 tobacco farmers accounted for $7.26 \%$. From the age structure of tobacco farmers engaged in tobacco cultivation, young farmers are the main body of tobacco cultivation. This also fully proves that the cultivation of tobacco smoke has a great appeal to the farmers of Guizhou province.

According to the cultural structure, the junior high school is $77.27 \%$, the high school or secondary school degree is $19.09 \%$, and the proportion with the above college education is $3.64 \%$. This indicates that the overall cultural level of tobacco farmers is low, which determines that tobacco farmers have a low level of cognition and management of the risk of tobacco cultivation, and they need external forces to intervene in tobacco and tobacco plant risk management.

From the age of tobacco smoke, it accounted for $5.45 \%$ of the two years, $23.64 \%$ in $2-5$ years, $49.09 \%$ in $5-10$ years, and $21.82 \%$ over 10 years. This indicates that the cultivation of cured tobacco is continuous, and the farmers 
who grow the cured tobacco are mostly farmers who have been cultivated for many years and have rich experience in planting. The farmers who have been newly added to the tobacco plant account for less.

From the income of tobacco and rural households, it is $50 \%$ farmers' income below 30,000 yuan. 30,000-50000 accounts for $30.91 \%$, 50000-100,000 accounts for $15.45 \%$, and more than 100,000 accounts for $3.64 \%$. On the whole, tobacco farmers have higher incomes. It also shows that the majority of farmers in Guizhou province are retail investors. But in general, tobacco farmers have weak resistance to risk.

\section{Construction of evaluation index system of insurance service quality}

This paper adopts the method of fuzzy comprehensive analysis, and establishes an indicator system by selecting a series of indicators. The established index system is divided into three levels, namely the target layer, the criterion layer and the sub-standard layer. The target layer is the objective of the evaluation of this thesis, namely the final measurement and evaluation of the satisfaction of tobacco agricultural insurance service. The criterion layer is the element content and insurance service process that the insurance service receiver pays attention to when receiving insurance service. The sub-criterion layer is the further embodiment and differentiation of the criterion layer. We divided the sub-criteria layer into 14 specific evaluation indicators, and the schematic diagram was shown as follows:

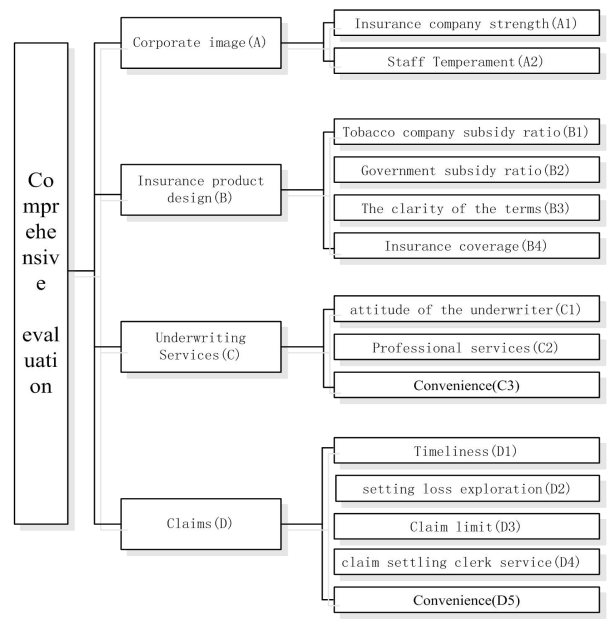

Figure1. evaluation index system diagram

\section{Establishment of evaluation model for insurance service quality}

\subsection{The overall thought}

This paper uses the method of fuzzy comprehensive analysis to establish a scientific and feasible comprehensive evaluation mathematical model. Fuzzy comprehensive analysis method's details are simplified to the following schematic diagram: 


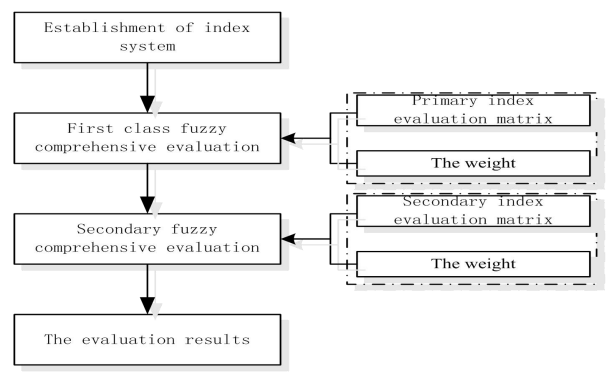

Figure 2 schematic diagram

corporate image accounts for $8 \%$. Each criterion of target layer can be seen in the effect of the weight. The rationality of the compensation amount and the proportion of government subsidies to farmers are the main factors which influence the service quality of insurance.

\section{Establish the fuzzy relation matrix $\mathbf{R}$}

Based on the statistical analysis of the

4.2. Establish concrete steps for evaluating the quality of insurance service

\section{Determine the factor set $\mathrm{U}$}

The insurance service quality evaluation indexes of the factors can be divided into corporate image design, insurance product design, underwriting services, and claims services.

\section{Determine the comment set $\mathrm{V}$}

The evaluation group is a collection of evaluation indexes of the respondents (farmers). $V=\{$ Very satisfied, satisfied, average, unsatisfied, very dissatisfied $\}$.

Determine the weight set $W$ of evaluation index

After data consolidation, Final weight $\mathrm{W}=(0.08,0.31,0.19,0.42)$. The weight of the above indicators can be seen that claim service has the largest impact on the satisfaction evaluation of tobacco agricultural insurance service system, accounting for $42 \%$ of the total. Secondly, insurance product design services accounts for $31 \%$; the underwriting service accounts for $19 \%$ and the

questionnaire results, four fuzzy relationship evaluation matrix of the evaluation of policy-based agricultural insurance service in Guizhou province were obtained.

$R_{1}=\left[\begin{array}{rrrrr}5 / 110 & 55 / 110 & 45 / 110 & 5 / 110 & 0 \\ 11 / 110 & 49 / 110 & 43 / 110 & 7 / 110 & 0\end{array}\right]$

$R_{2}=\left[\begin{array}{rrrll}10 / 110 & 62 / 110 & 36 / 110 & 2 / 110 & 0 \\ 8 / 110 & 52 / 110 & 41 / 110 & 8 / 110 & 1 / 110 \\ 7 / 110 & 43 / 110 & 46 / 110 & 14 / 110 & 0 \\ 5 / 110 & 55 / 110 & 44 / 110 & 6 / 110 & 0\end{array}\right]$

$R_{3}=\left[\begin{array}{lllll}7 / 110 & 46 / 110 & 54 / 110 & 3 / 110 & 0 \\ 8 / 110 & 50 / 110 & 49 / 110 & 3 / 110 & 0 \\ 6 / 110 & 61 / 110 & 37 / 110 & 5 / 110 & 1 / 110\end{array}\right]$

$R_{4}=\left[\begin{array}{rrrrl}8 / 110 & 44 / 110 & 45 / 110 & 12 / 110 & 1 / 110 \\ 7 / 110 & 56 / 110 & 37 / 110 & 9 / 110 & 1 / 110 \\ 6 / 110 & 57 / 110 & 37 / 110 & 10 / 110 & 0 \\ 7 / 110 & 38 / 110 & 48 / 110 & 17 / 110 & 0 \\ 6 / 110 & 34 / 110 & 53 / 110 & 15 / 110 & 2 / 110\end{array}\right]$

Calculate the fuzzy comprehensive evaluation vector $S$

With the tobacco agricultural insurance service satisfaction survey analyzed, we calculated the relationship between each evaluation index weight value and fuzzy evaluation matrix.

$S=[0.0679,0.4,04775,0.054,0.0016]$ 
According to the above results, the following conclusions can be drawn: $6.79 \%$ of farmers surveyed were pleased with the tobacco agricultural insurance services; $40 \%$ of farmers surveyed were satisfied; $47.75 \%$ of farmers feel average; $5.4 \%$ of farmers are dissatisfied. $0.16 \%$ of farmers surveyed were very dissatisfied.

\section{Problems existing in the tobacco agricultural insurance system in Guizhou province and related Suggestions}

Through field investigation and research on tobacco agricultural insurance service satisfaction in Guizhou above the satisfaction evaluation of Guizhou province tobacco agricultural insurance service system analysis, summed up the tobacco agricultural insurance service system in Guizhou exist some problems such as: grass-roots service personnel lack of propaganda, single agricultural insurance products, insurance clause design arcane, insurance company claims survey is difficult, the settling time is long, insurance companies and government departments lack of linkage mechanism, etc. For the above questions, the insurer should improve service consciousness and strengthen agricultural insurance products' design, and the insurer also should blaze a specialized path for agricultural insurance technology and enhance propaganda. The government needs to clarify the responsibilities of all departments and improve the linkage mechanism.

\section{References}

[1] Gu Minghua, “On the development of agricultural insurance -- take Guizhou province as an example", Legal and Economy, 141-143,2011.

[2] Zhang Zundong, Mao Yin, "Empirical analysis on the influence factors of agricultural insurance development in Guizhou province". Guizhou Agricultural Sciences, 239-242, 2013.

[3] Guo Yongli, "The highlights and difficulties of the agricultural insurance regulations". China Insurance, 19-20, 2013.

[4] Guan Shiyun, Ma Shaodong, Tan Haiyan, "Research on agricultural insurance development under the background of new-type urbanization", Knowledge Economy, 9-10, 2014. 